九州大学学術情報リポジトリ

Kyushu University Institutional Repository

\title{
マウス腫瘍微小環境におけるPD-L1とPD-L2の抗腫瘍 免疫抑制機能
}

梅津，大輔

http://hdl. hand le. net/2324/2236121

出版情報：Kyushu University，2018，博士（医学），課程博士 バージョン：

権利関係 : 
Title

Inhibitory functions of PD-L1 and PD-L2 in the regulation of anti-tumor immunity in murine tumor microenvironment

\section{Authors}

Daisuke Umezu ${ }^{1,2}$, Nana Okada ${ }^{1}$, Yukimi Sakoda ${ }^{1}$, Keishi Adachi ${ }^{1}$, Toshiyasu Ojima ${ }^{3}$, Hiroki Yamaue $^{3}$, Masatoshi Eto², Koji Tamada ${ }^{1}$

\section{Authors' affiliations}

1Department of Immunology, Yamaguchi University Graduate School of Medicine, Ube, Japan

${ }^{2}$ Department of Urology, Graduate School of Medical Sciences, Kyushu University, Fukuoka, Japan

3Second Department of Surgery, Wakayama Medical University, School of Medicine, Wakayama, Japan 


\section{Corresponding Author}

Koji Tamada, M.D., Ph.D.

Department of Immunology, Yamaguchi University Graduate School of Medicine

1-1-1 Minami Kogushi, Ube, Yamaguchi, Japan, 755-8505

Email:ktamada@yamaguchi-u.ac.jp

Phone number; +81-836-22-2341

\section{Keywords}

PD-L1, PD-L2, tumor-associated macrophages, tumor microenvironment

\section{Précis}

PD-L1 expressed on tumor cells and bone marrow-derived hematopoietic cells, as well as

PD-L2 inducibly expressed on tumor-associated macrophages, play an important role in the suppression of anti-tumor immune responses. 


\section{Abstract}

Although a role of PD-L1 in the suppression of anti-tumor immunity and its value as a predictive biomarker have been suggested by various preclinical and clinical studies, precise mechanisms how PD-L1 and PD-L2, another ligand of PD-1, regulate anti-tumor immunity in the tumor microenvironment have yet to be fully explored. Here we address this issue by using PD-L1-deficient tumor cell, PD-L1-knockout (KO) mice, anti-PD-L1 monoclonal antibody (mAb), and anti-PD-L2 mAb. First, PD-L1-deficient or competent tumor cells were inoculated into wild-type or PD-L1-KO mice. Results of tumor growth and mouse survival indicated that both tumor- and host-derived PD-L1 are functional to suppress anti-tumor immunity, while the former contributes predominantly than the latter. Experiments using bone marrow (BM) chimeric mice generated by a transfer of PD-L1-KO BM cells into wild-type mice or vice versa further suggested that PD-L1 expressed on BM-derived hematopoietic cells mediates the suppressive effects on antitumor immunity. Second, anti-PD-L2 mAb treatment demonstrated a profound synergy with anti-PD-L1 mAb therapy, whereas anti-PD-L2 mAb alone hardly induced any antitumor effects, suggesting that PD-L2 functions become evident when the effects of PDL1 are abrogated by anti-PD-L1 mAb. Consistently with this notion, PD-L2 expression was upregulated on tumor-associated macrophages (TAM) when the mice were treated 
with anti-PD-L1 mAb. Taken together, our study elucidated an importance of PD-L1

associated with tumor cells and non-tumor host cells, particularly BM-derived hematopoietic cells, as well as PD-L2 inducibly expressed on TAM in the suppression of anti-tumor immunity in the tumor microenvironment.

\section{Abbreviations}

BM: bone marrow

i.p.: intraperitoneally

KO: knockout

mAb: monoclonal antibody

mAbs: monoclonal antibodies

PD-1: programmed cell death-1

PD-L1: programmed cell death-ligand 1

PD-L2: programmed cell death-ligand 2

s.c.: subcutaneously

TAM: tumor-associated macrophages 


\section{Introduction}

Immune checkpoint blockade therapies targeting programmed cell death-1 (PD-1) and programmed cell death-ligand 1 (PD-L1) have demonstrated significant clinical benefits superior to the standard therapies in various types of advanced cancers, thus causing paradigm shift in the treatment of cancer [1-3]. In spite of broad clinical applications, molecular and cellular mechanisms of PD-1/PD-L1 blockade have yet to be fully explored. In particular, it remains unknown which cells are targeted by PD-1/PD-L1 blockade therapy and how it modifies immune responses in the tumor microenvironment. Exploring these issues is highly important, as it could reveal novel biomarkers associated with positive responses in $\mathrm{PD}-1 / \mathrm{PD}-\mathrm{L} 1$ blockade therapy and may contribute to identify novel targets of cancer immunotherapy.

One crucial and unsolved issue is whether PD-L1 on tumor cells or non-tumor host cells is responsible for the suppressive functions in anti-tumor $\mathrm{T}$ cell responses, and which of these cells are primary targets of anti-PD-1/PD-L1 monoclonal antibodies (mAbs). In this regard, data from various clinical studies have demonstrated that PD-L1 expression level on tumor cells can be used as a predictive biomarker of patients who will display clinical benefits by these therapies [4,5]. On the other hand, it was also reported that PD-L1 positivity on tumor cells shows no correlation with therapeutic 
benefits of anti-PD-1 mAb [6]. Other studies further indicated that PD-L1 expression on immune cells infiltrating in tumor tissues was associated with a higher response rate in patients treated with PD-1/PD-L1 blockade [7]. To experimentally investigate this issue, preclinical studies using PD-L1-deficient tumor cells and PD-L1-knockout (KO) mice have been conducted by several groups [8-13]. Inconsistent results have been reported in these studies, as crucial roles of PD-L1 on both tumor and non-tumor host cells [8-10], predominantly on tumor cells [11] or non-tumor host cells [12,13] have been suggested. Currently, a relative importance of PD-L1 on tumor cells versus non-tumor host cells in the suppression of anti-tumor immunity as well as in PD-1/PD-L1 blockade therapy remains controversial and thus warrants further investigation.

PD-1 delivers an inhibitory signal by interaction with programmed cell death-ligand 2 (PD-L2) as well as PD-L1 [14]. Therefore, another important question is whether or not PD-L2 expression in the tumor tissues could play any roles in the suppression of antitumor immunity, and if so, how and what types of cells express PD-L2 in the tumor microenvironment. Although PD-L2 expression was initially thought to be restricted on macrophages and dendritic cells upon stimulation with IFN-Y, GM-CSF, or IL-4 [15], recent studies have indicated that various types of tumor cells and non-tumor host cells, including immune cells, endothelial cells and fibroblasts, express PD-L2 [16-18]. 
Regarding a role of PD-L2 in the regulation of anti-tumor immunity, it remains controversial as one study demonstrated a significant correlation of PD-L2 expression with clinical benefits by anti-PD-1 mAb therapy [17], while another did not observe such correlation [19]. Thus, it is of importance to explore potential roles of PD-L2 in the suppression of anti-tumor immunity and the resistance to PD-1/PD-L1 blockade therapies.

In this study, we explored a relative importance of PD-L1 expressions on tumor cells and non-tumor host cells including bone marrow (BM)-derived hematopoietic cells in the regulation of anti-tumor immunity. In addition, an importance of PD-L2 expression on tumor-associated macrophages (TAM) as a biomarker and a therapeutic target in immune checkpoint blockade was investigated. 


\section{Materials and methods}

Mice

PD-L1-KO mice with C57BL/6 background were originally generated by Lieping Chen

[20] (Yale University, CT). All mice were maintained under specific pathogen-free conditions in the animal facility at Yamaguchi University (Ube, Japan).

\section{Tumor cell line}

3LL and B16F10 is mouse lung carcinoma and mouse melanoma cell line, respectively.

MC38 is mouse colon carcinoma cell line [21]. These cell lines were maintained in RPMI supplemented with 10\% FBS, 1\% penicillin-streptomycin, $25 \mathrm{mM}$ HEPES, and $50 \mathrm{mM}$ 2-mercaptoethanol.

\section{Generation of PD-L1-deficient MC38 cell line}

To generate MC38 cell line lacking PD-L1 expression, we designed the single-guide RNA targeting mouse PD-L1 (5'-TCCAAAGGACTTGTACGTGG-3'). Lentivirus particles (U6gRNA/Puro-Cas9-GFP) were purchased from Sigma-Aldrich and transfected into MC38 cells in the presence of polybrene (hexadimethrine bromide, Sigma-Aldrich). After 
puromycin selection, a single cell of GFP-positive MC38 was isolated by FACS (SH800, Sony). Control MC38 cell line was generated in the same manner by using CRISPR-lenti Non-targeting Control Transduction Particles (Sigma-Aldrich). Expression levels of PDL1/L2 and MHC class I/II on these cell lines were examined by flow cytometry (BD LSRFortessa X-20, BD Biosciences) after staining with following reagents; PEconjugated anti-PD-L1 mAb (clone M1H5, eBioscience), PE-conjugated anti- $\mathrm{H}-2 \mathrm{~Kb}$ mAb (clone AF6-88.5, BD Biosciences), PE-conjugated anti-H-2Db mAb (clone KH95, Biolegend), PE-conjugated anti-I-Ab mAb (clone AF6-120.1, BD Biosciences), and APCconjugated anti-PD-L2 mAb (clone TY25, BD Biosciences). In some experiments, MC38 cell lines were incubated in the presence of mouse IFN-Y (Biolegend) prior to the analyses.

\section{In vivo tumor models}

Wild-type C57BL/6 mice or PD-L1-KO mice were inoculated subcutaneously (s.c.) with 1 $\times 10^{6}$ PD-L1-deficient or control MC38 in the right lateral flank. In some experiments, wild-type C57BL/6 mice were inoculated s.c. with $1 \times 10 \square$ 3LL tumor cells. These tumor cells were suspended in HBSS prior to the injections. As for Ab treatment, $200 \mathrm{ug}$ of hamster IgG (Innovative Research), rat IgG (Sigma-Aldrich), anti-mouse PD-L1 mAb (clone 10B5) [22] or anti-mouse PD-L2 mAb (clone TY25, purchased from BioXcell) were 
injected intraperitoneally (i.p.) on days 4, 9, 14, 19 and 24 after tumor inoculation. Tumor growth was measured at least twice a week with a digital caliper, and tumor volume was calculated using the following formula; $\mathrm{x} \times \mathrm{y}^{2} / 2$, where $\mathrm{x}$ is the long diameter and $\mathrm{y}$ is the short diameter of the tumor. Mice were euthanized when tumor volume reached $4,000 \mathrm{~mm}^{3}$ or severe ulceration with bleeding in the tumor was observed.

\section{Bone marrow chimeric mice}

BM cells were harvested from wild-type or PD-L1-KO mice by flushing marrow cavity of femur with RPMI medium. After lysis of RBC with ACK Lysing Buffer (Lonza), BM cells were suspended with HBSS, passed through cell strainers, and counted. Recipient wildtype or PD-L1-KO mice were given lethal dose irradiation consisting of split 6 Gy doses twice 6-8 hours apart (total $12 \mathrm{~Gy}$ ), followed by intravenous injection of $7.5 \times 10^{6} \mathrm{BM}$ cells per mouse. At least six weeks later, BM chimeric mice were inoculated s.c. with $1 \times$ $10 \square$ PD-L1-deficient MC38 cells.

\section{Analysis of tumor tissue by flow cytometer}

Wild-type C57BL/6 mice were inoculated s.c. with MC38 and treated with hamster IgG $\mathrm{Ab}$ or anti-PD-L1 mAb on days 4. On days 9, tumor tissues were resected and minced 
with scissors, followed by digestion with medium containing liberase TL (Roche) and DNase I (Roche) for 2 hours at room temperature. Digested tumor samples were homogenized by repetitive pipetting and passed through cell strainers to generate singlecell suspensions. Tumor-infiltrating immune cells were separated from tumor and stromal cells by magnetic cell sorting using anti-mouse CD45 mAb (Miltenyi Biotec). CD45-negative populations were stained with APC-conjugated anti-PD-L2 mAb (clone TY25, BD Biosciences). CD45-positive populations were stained with following mAbs; BV421-conjugated anti-CD11b mAb (clone M1/70, BD Biosciences), PE-Cy7-conjugated anti-F4/80 mAb (clone BM8, Biolegend), and APC-conjugated anti-PD-L2 mAb (clone TY25, BD Biosciences). TAM were identified as a population double positive of CD11b and F4/80 within CD45-positive cells, while the remaining populations (i.e. CD11b and F4/80-single positive or double negative) within CD45-positive cells were identified as non-TAM immune cells including T cells. Expression levels of PD-L2 on the cells of tumor tissues were examined by flow cytometer (BD LSRFortessa X-20), and the data were analyzed by using FlowJo software (FlowJo, LLC). All the cells were pre-incubated with anti-CD16/32 mAb (Fc block, clone 2.4G2, BD Biosciences) prior to staining in order to block non-specific binding of mAbs. 


\section{Rechallenge of tumor}

The mice which had rejected MC38 tumor by the combined treatment with anti-PD-L1 and anti-PD-L2 mAbs were rechallenged s.c. with MC38 and B16F10 in the right and left lateral flank, respectively, 3 months after the original tumor inoculation. As a control, naïve C57BL/6 mice were also inoculated s.c. with MC38 and B16F10 in the same manner. Tumor growth was measured at least twice a week with a digital caliper.

\section{Statistical analysis}

JMP 13 (SAS Institute Inc., Cary, NC) was used for statistical analysis. The 2-tailed

Student $t$-test was applied to compare 2 groups. For survival data, Kaplan-Meier survival curves were prepared, and statistical differences were analyzed by using the log-rank test. $P<0.05$ was considered as statistically significant. 


\section{Results}

PD-L1 on tumor cells as well as non-tumor cells mediates suppression of anti-tumor immune responses

Expressions of PD-L1 in the tumor microenvironment are detectable on both tumor cells and non-tumor cells including stromal and infiltrating immune cells. First, to explore a relative importance of PD-L1 expressed on tumor or non-tumor cells, we developed a model in which PD-L1-deficient or competent tumor cells were inoculated into PD-L1KO or wild-type mice. PD-L1-deficient tumor cells were generated from MC38 mouse colon carcinoma by CRISPR/Cas9 gene-editing method. PD-L1-deficient MC38 did not express PD-L1 even in the presence of IFN`ץ, while control MC38 treated with scramble gRNA CRISPR/Cas9 showed a significant upregulation of PD-L1 in response to IFN-Y (Supplementary Fig. 1a). It is also confirmed that expression levels of MHC class I were comparable between PD-L1-deficient and control MC38 cell lines (Supplementary Fig. 1b). Intensity of MHC class I upregulation by stimulation with IFN-ץ was also equivalent in these cell lines. Neither PD-L2 nor MHC class II were expressed on these cell lines in the presence or absence of IFN-Y (Supplementary Fig. 1a, b).

To explore importance of PD-L1 expressed on tumor cells or non-tumor cells in the 
suppression of anti-tumor immunity, PD-L1-deficient or control MC38 cells were s.c. into PD-L1-KO or wild-type mice. While control MC38 grew up in all cases when inoculated in wild-type mice, PD-L1-deficient MC38 showed a significant delay of tumor growth and resulted in tumor rejection in 6 out of 15 mice (Fig. 1a). Survival of mice was also significantly prolonged in the wild-type mice inoculated with PD-L1-deficient MC38 (Fig. 1b). When control MC38 cells were inoculated in PD-L1-KO mice, tumor rejection was observed in 1 out of 17 mice along with delay of tumor growth and prolonged mouse survival. Importantly, when PD-L1-deficient MC38 cells were inoculated into PD-L1-KO mice, complete tumor rejection and long-term survival were observed in 16 out of 17 mice. Taken together, these results suggested that PD-L1 on tumor cells and non-tumor host cells are both important for suppression of anti-tumor immunity, while PD-L1 on tumor cells would rather make a primary contribution.

Important role of PD-L1 on bone marrow-derived hematopoietic cells in the suppression of anti-tumor immunity

Our data revealed a potential role of PD-L1 expressed on non-tumor host cells in the suppression of anti-tumor immunity. However, it remains unclear whether stromal nonimmune cells or infiltrating immune cells are responsible for this effect, since PD-L1 can 
be detected on various host cells including endothelial cells and cancer-associated fibroblasts [23,18]. To address this question, BM chimeric mice, in which wild-type mice were treated with systemic myeloablative irradiation followed by a transfer of BM cells of PD-L1-KO mice (PD-L1-KO BM into wild-type mice), were generated. In addition, the mice with BM transfer vice versa (wild-type BM into PD-L1-KO mice) were also generated. These BM chimeric mice were inoculated s.c. with PD-L1-deficient MC38. In PD-L1-KO BM into wild-type mice, the tumor was rejected in all the cases (Fig. 2). On the other hand, eventual tumor growth was observed in 4 out of 10 cases in wild-type BM into PD-L1-KO mice. These results suggested that, among non-tumor host cells, PDL1 expressed on BM-derived hematopoietic cells including immune cells plays a major role in the suppression of anti-tumor immunity.

\section{Anti-tumor effects of PD-L1 and PD-L2 blockade in MC38 tumor model}

Inhibitory signal into PD-1 can be delivered by its interaction with PD-L2 as well as PD-

L1 [14]. To explore a potential role of PD-L2 in the suppression of anti-tumor immunity and its relevance to $\mathrm{PD}-\mathrm{L} 1$ functions, the mice inoculated with MC38 were treated with anti-PD-L2 mAb with or without anti-PD-L1 mAb. As control, rat IgG and hamster IgG were injected, respectively. Treatment with anti-PD-L2 mAb alone induced hardly any 
anti-tumor effects, as shown that tumor growth and mouse survival were equivalent to those treated with control Abs (Fig. 3). On the other hand, treatment with anti-PD-L1 $\mathrm{mAb}$ alone significantly inhibited tumor growth and induced tumor rejection in 5 out of 12 mice, resulting in a prolonged mouse survival. When anti-PD-L2 mAb was injected in combination with anti-PD-L1 mAb, the tumor growth was further inhibited and resulted in tumor rejection in 11 out of 12 mice. Survival of the mice treated with both anti-PDL1 and anti-PD-L2 mAbs was significantly prolonged compared to those treated with anti-PD-L1 mAb alone. These results suggested that suppressive effects of PD-L2 were undetectable by itself, but became evident under the condition that PD-L1/PD-1 interaction was ablated.

\section{Enhanced expression of PD-L2 on tumor-associated macrophages by PD-L1 blockade}

To investigate the mechanism by which the effects of PD-L2 become evident along with

PD-L1 blockade, expression levels of PD-L2 on cells in the tumor microenvironment including tumor cells and infiltrating immune cells were analyzed in the absence or presence of anti-PD-L1 mAb treatment. Mice were inoculated with MC38 on day 0, and then treated with anti-PD-L1 mAb or control $\mathrm{Ab}$ on day 4. On days 9, tumor tissues were harvested and digested to single cell suspension, followed by separation into CD45- 
positive immune cells and CD45-negative non-immune cells by magnetic sorting. Expression levels of PD-L2 were assessed by flow cytometry, in which TAM were identified as $\mathrm{CD} 45^{+} \mathrm{CD} 11 \mathrm{~b}+\mathrm{F} 4 / 80^{+}$cells while the remaining $\mathrm{CD} 45^{+}$subsets, i.e. CD $11 \mathrm{~b}$, F4/80 single-positive or double-negative, were considered to be non-TAM immune cells including T cells, B cells, NK cells and dendritic cells. In the absence of anti-PD-L1 mAb treatment, slight expressions of PD-L2 were detected on TAM, but not other CD45+ subsets (Fig. 4). When the mice were treated with anti-PD-L1 mAb, PD-L2 expression on TAM, but not other CD45 subsets, significantly increased. There were no significant differences in the number of CD45-positive immune cells in the tumor tissue and the percentage of TAM between control $\mathrm{Ab}^{-}$and anti-PD-L1 mAb-treated groups (data not shown). No expression of PD-L2 was detected on CD45-negative non-immune cells, which include tumor cells, irrespective of the treatment with anti-PD-L1 mAb. These results revealed that PD-L2 expression was inducibly upregulated on TAM in the presence of PD-L1 blockade.

Long-term anti-tumor memory responses induced by the treatment with anti-PD-L1 and anti-PD-L2 mAbs

Combined treatment of anti-PD-L1 and anti-PD-L2 mAbs achieved MC38 tumor 
rejection in almost all the mice, resulted in the prolonged survival over 100 days. To confirm the generation of tumor-specific memory responses by this treatment, the survived mice were rechallenged with $\mathrm{MC} 38$ or B16F10, melanoma cells syngeneic to C57BL/6 mice but unrelated to MC38 in terms of antigenicity. It was found that all the tumor-survived mice were resistant to rechallenge with MC38 but not B16F10 (Fig. 5). As a control, MC38 and B16F10 inoculated into naïve C57BL/6 mice in the same manner led to apparent tumor growth. This result indicated that combined blockade of PD-L1 and PD-L2 could induce tumor-specific long-term memory responses.

\section{Therapeutic effects of anti-PD-L1 and anti-PD-L2 mAbs in 3LL lung tumor}

The therapeutic effects of combined treatment with anti-PD-L1 and anti-PD-L2 mAbs were further examined in another tumor model using 3LL, Lewis lung carcinoma. The mice inoculated s.c. with 3LL tumor were treated with anti-PD-L1 mAb, anti-PD-L2 mAb, or both of these mAbs. As shown in Figure 6, combined therapy of anti-PD-L1 and antiPD-L2 mAbs significantly inhibited 3LL tumor growth, resulted in a prolonged mouse survival compared with the other groups ( $P=0.013$ vs. control Abs, $P=0.021$ vs. anti-PDL1 mAb, $P=0.021$ vs. anti-PD-L2 mAb). No significant differences in survival were observed among other groups. This result indicated that synergistic anti-tumor effects 
by simultaneous blockade of PD-L1 and PD-L2 were also detectable in 3LL lung tumor model. 


\section{Discussion}

In this study, we attempted to elucidate molecular and cellular mechanisms by which

PD-L1 and PD-L2 inhibit anti-tumor T cell responses in the tumor microenvironment.

Our findings indicated that PD-L1 on both tumor cells and non-tumor host cells mediates inhibitory effects, while tumor-associated PD-L1 would play a predominant role. Among non-tumor host cells, PD-L1 on BM-derived hematopoietic cells was found to be essential.

Although PD-L2 mediated almost no effects in the presence of PD-L1/PD-1 interaction, its immune-inhibitory effects became evident through inducible expressions on TAM when PD-L1/PD-1 interaction was attenuated. These findings would provide useful insights into clinical applications of PD-1/PD-L1 blockade therapies regarding identification of accurate biomarkers and development of efficient immunotherapies.

Several previous studies have explored an importance of PD-L1 expressed on tumor cells and non-tumor host cells by utilizing PD-L1-deficient tumor lines and/or PD-L1-KO mice [8-13]. While these studies reached inconsistent observations, i.e. crucial roles of PD-L1 on both tumor and non-tumor cells, predominantly that on tumor cells, or host cells, these results were probably due to differences in experimental models including immunogenicity of tumors and injection doses of cells and reagents. In this regard, our study indicated that both tumor- and host-derived PD-L1 could inhibit anti-tumor 
immune responses. It should be noted that our findings further indicated more primary role of PD-L1 on tumor cells than that on host cells, based on direct comparison between wild-type mice inoculated with PD-L1-deficient tumor and PD-L1-KO mice inoculated with control tumor. Among host cells, PD-L1 associated with BM-derived hematopoietic cells, but not non-hematopoietic cells, plays an essential role in the suppression of antitumor immune responses, consistently with previous studies indicating an importance of PD-L1 on macrophages and dendritic cells [12,13]. These preclinical studies collectively suggest that PD-L1 on tumor cells and host hematopoietic cells are both functional to suppress anti-tumor T cell immunity, while its relative importance would change depending on various factors including tumor immunogenicity and endogenous expression of PD-L1 by genetic and/or epigenetic control. Further studies utilizing clinical samples of various cancers would be required to fully explore a role of PD-L1 in the tumor microenvironment.

While an importance of PD-L2 as a target and potential biomarker of anti-PD-1 mAb therapy has been suggested [17], precise mechanisms how PD-L2 inhibits T cell immunity at the tumor microenvironment remained unexplored. Our findings in this study revealed that PD-L2 expression is upregulated on TAM and its inhibitory effects become evident when PD-L1 functions are abrogated by anti-PD-L1 mAb. This result 
implicates that, although PD-L1/PD-1-dependent suppression is a primary mechanism of immune evasion in cancer, alternative mechanisms including PD-L2 upregulation could compensate once PD-L1 functions are dampened. These findings would be consistent with previous reports that presence of TAM correlates with poor prognosis in human cancers [24], and that PD-L2 could be expressed on non-tumor cells according to tumor cell types and the conditions of tumor microenvironment [17]. Regarding molecular mechanisms how PD-L2 expression is induced by PD-L1 blockade, it was reported that PD-L2 on TAM is upregulated by IL-27 via Stat3 activation [25]. While detailed mechanism of PD-L2 upregulation in our study remains unclear, we infer that changes in cytokine milieu at the tumor microenvironment by anti-PD-L1 mAb treatment could trigger the expression of $\mathrm{PD}^{-\mathrm{L} 2}$. IFN-Y might play a certain role, as it was reported that IL-27 production by macrophages can be induced by IFN-Y-mediated pathways [26].

In addition to PD-L2, various inhibitory mechanisms including PD-1-independent immune checkpoint molecules, regulatory $\mathrm{T}$ cells, and suppressive cytokines/enzymes, might also mediate compensatory effects when PD-L1/PD-1 system is abrogated. Consistently with this notion, upregulation of TIM- 3 in response to anti-PD- 1 mAb treatment was reported [27]. Furthermore, combined therapy of anti-PD-1 mAb with 
anti-TIM-3, LAG-3, or TIGIT mAb induced remarkable synergy to enhance the antitumor effects of anti-PD-1 mAb, whereas monotherapy of anti-TIM-3, LAG-3, or TIGIT mAb hardly displayed any therapeutic potential [28-30], suggesting that these checkpoint molecules become adaptively functional following PD-1 blockade. Taken together, adaptive resistance of tumor is highly dynamic process which could be affected by endogenous $\mathrm{T}$ cell responses as well as exogenous medical interventions including immunotherapies. Serial evaluation of immune-regulatory molecules before and after immunotherapies would be necessary for development of effective combination immunotherapies as well as identification of highly predictive biomarkers. 


\section{Acknowledgements}

The authors thank Shunsuke Goto, Hiromi Kurosawa and Makiko Miyamoto for excellent technical assistance.

\section{Author contributions}

Daisuke Umezu, Nana Okada, Yukimi Sakoda, and Keishi Adachi conducted experiments. Toshiyasu Ojima, Hiroki Yamaue, Masatoshi Eto, and Koji Tamada guided the conduct of experiments. Daisuke Umezu and Koji Tamada wrote the manuscript.

\section{Funding}

This study was supported by research funds from Grant-in-Aid for Scientific Research 16H02474 and Ono Pharmaceutical Inc. 


\section{Compliance with Ethical Standards}

\section{Conflict of Interest}

Koji Tamada received research fund from Ono Pharmaceutical Inc. Other authors

declare no conflict of interest.

\section{Ethical approval}

All applicable international, national, and/or institutional guidelines for the care and use of animals were followed. All procedures performed in studies involving animals were in accordance with the ethical standards of the institution or practice at which the studies were conducted. Institutional approval number of animal experiment is 14-001.

\section{Animal source}

Male or female 6 to 12-weeks old wild-type C57BL/6 mice were purchased from Japan SLC (Shizuoka, Japan). PD-L1-KO mice with C57BL/6 background were kindly provided by Lieping Chen.

\section{Cell line authentication}


MC38 mouse colon carcinoma cell line was kindly provided by F. James Primus. 3LL mouse lung carcinoma cell line and B16F10 mouse melanoma cell line was purchased from Japanese Collection of Research Bioresources Cell Bank and ATCC, respectively, who had authenticated them. 


\section{References}

1. Topalian SL, Hodi FS, Brahmer JR, Gettinger SN, Smith DC, McDermott DF, Powderly JD, Carvajal RD, Sosman JA, Atkins MB, Leming PD, Spigel DR, Antonia SJ, Horn L, Drake CG, Pardoll DM, Chen L, Sharfman WH, Anders RA, Taube JM, McMiller TL, Xu H, Korman AJ, Jure-Kunkel M, Agrawal S, McDonald D, Kollia GD, Gupta A, Wigginton JM, Sznol M (2012) Safety, activity, and immune correlates of anti-PD-1 antibody in cancer. N Engl J Med 366 (26):2443-2454. doi:10.1056/NEJMoa1200690

2. Brahmer JR, Tykodi SS, Chow LQ, Hwu WJ, Topalian SL, Hwu P, Drake CG, Camacho LH, Kauh J, Odunsi K, Pitot HC, Hamid O, Bhatia S, Martins R, Eaton K, Chen S, Salay TM, Alaparthy S, Grosso JF, Korman AJ, Parker SM, Agrawal S, Goldberg SM, Pardoll DM, Gupta A, Wigginton JM (2012) Safety and activity of anti-PD-L1 antibody in patients with advanced cancer. N Engl J Med 366 (26):2455-2465. doi:10.1056/NEJMoa1200694

3. Ribas A, Wolchok JD (2018) Cancer immunotherapy using checkpoint blockade. Science 359 (6382):1350-1355. doi:10.1126/science.aar4060

4. Garber K (2015) Predictive biomarkers for checkpoints, first tests approved. Nat Biotechnol 33 (12):1217-1218. doi:10.1038/nbt1215-1217

5. Reck M, Rodriguez-Abreu D, Robinson AG, Hui R, Csoszi T, Fulop A, Gottfried M, Peled N, 
Tafreshi A, Cuffe S, O'Brien M, Rao S, Hotta K, Leiby MA, Lubiniecki GM, Shentu Y,

Rangwala R, Brahmer JR (2016) Pembrolizumab versus Chemotherapy for PD-L1-

Positive Non-Small-Cell Lung Cancer. N N Engl J $\quad$ Med 375 (19):1823-1833.

doi:10.1056/NEJMoa1606774

6. Motzer RJ, Escudier B, McDermott DF, George S, Hammers HJ, Srinivas S, Tykodi SS,

Sosman JA, Procopio G, Plimack ER, Castellano D, Choueiri TK, Gurney H, Donskov F,

Bono P, Wagstaff J, Gauler TC, Ueda T, Tomita Y, Schutz FA, Kollmannsberger C, Larkin

J, Ravaud A, Simon JS, Xu LA, Waxman IM, Sharma P, CheckMate I (2015) Nivolumab

versus Everolimus in Advanced Renal-Cell Carcinoma. N Engl J Med 373 (19):1803-1813.

doi:10.1056/NEJMoa1510665

7. Rosenberg JE, Hoffman-Censits J, Powles T, van der Heijden MS, Balar AV, Necchi A,

Dawson N, O'Donnell PH, Balmanoukian A, Loriot Y, Srinivas S, Retz MM, Grivas P, Joseph RW, Galsky MD, Fleming MT, Petrylak DP, Perez-Gracia JL, Burris HA, Castellano D, Canil C, Bellmunt J, Bajorin D, Nickles D, Bourgon R, Frampton GM, Cui N, Mariathasan S, Abidoye O, Fine GD, Dreicer R (2016) Atezolizumab in patients with locally advanced and metastatic urothelial carcinoma who have progressed following treatment with platinum-based chemotherapy: a single-arm, multicentre, phase 2 trial. Lancet 387 (10031):1909-1920. doi:10.1016/S0140-6736(16)00561-4 
8. Noguchi T, Ward JP, Gubin MM, Arthur CD, Lee SH, Hundal J, Selby MJ, Graziano RF, Mardis ER, Korman AJ, Schreiber RD (2017) Temporally Distinct PD-L1 Expression by Tumor and Host Cells Contributes to Immune Escape. Cancer Immunol Res 5 (2):106-117. doi:10.1158/2326-6066.CIR-16-0391

9. Lau J, Cheung J, Navarro A, Lianoglou S, Haley B, Totpal K, Sanders L, Koeppen H, Caplazi P, McBride J, Chiu H, Hong R, Grogan J, Javinal V, Yauch R, Irving B, Belvin M, Mellman I, Kim JM, Schmidt M (2017) Tumour and host cell PD-L1 is required to mediate suppression of anti-tumour immunity in mice. Nature communications 8:14572. doi:10.1038/ncomms14572

10. Kleinovink JW, Marijt KA, Schoonderwoerd MJA, van Hall T, Ossendorp F, Fransen MF (2017) PD-L1 expression on malignant cells is no prerequisite for checkpoint therapy. Oncoimmunology 6 (4):e1294299. doi:10.1080/2162402X.2017.1294299

11. Juneja VR, McGuire KA, Manguso RT, LaFleur MW, Collins N, Haining WN, Freeman GJ, Sharpe AH (2017) PD-L1 on tumor cells is sufficient for immune evasion in immunogenic tumors and inhibits CD8 T cell cytotoxicity. J Exp Med 214 (4):895-904. doi:10.1084/jem.20160801

12. Tang H, Liang Y, Anders RA, Taube JM, Qiu X, Mulgaonkar A, Liu X, Harrington SM, Guo J, Xin Y, Xiong Y, Nham K, Silvers W, Hao G, Sun X, Chen M, Hannan R, Qiao J, 
Dong H, Peng H, Fu YX (2018) PD-L1 on host cells is essential for PD-L1 blockade-

mediated tumor regression. The Journal of clinical investigation 128 (2):580-588. doi:10.1172/JCI96061

13. Lin H, Wei S, Hurt EM, Green MD, Zhao L, Vatan L, Szeliga W, Herbst R, Harms PW, Fecher LA, Vats P, Chinnaiyan AM, Lao CD, Lawrence TS, Wicha M, Hamanishi J, Mandai M, Kryczek I, Zou W (2018) Host expression of PD-L1 determines efficacy of PDL1 pathway blockade-mediated tumor regression. The Journal of clinical investigation 128 (2):805-815. doi:10.1172/JCI96113

14. Latchman Y, Wood CR, Chernova T, Chaudhary D, Borde M, Chernova I, Iwai Y, Long AJ, Brown JA, Nunes R, Greenfield EA, Bourque K, Boussiotis VA, Carter LL, Carreno BM, Malenkovich N, Nishimura H, Okazaki T, Honjo T, Sharpe AH, Freeman GJ (2001) PDL2 is a second ligand for PD-1 and inhibits T cell activation. Nat Immunol 2 (3):261-268. doi:10.1038/85330

15. Yamazaki T, Akiba H, Iwai H, Matsuda H, Aoki M, Tanno Y, Shin T, Tsuchiya H, Pardoll DM, Okumura K, Azuma M, Yagita H (2002) Expression of Programmed Death 1 Ligands by Murine T Cells and APC. The Journal of Immunology 169 (10):5538-5545. doi:10.4049/jimmunol.169.10.5538

16. Messal N, Serriari NE, Pastor S, Nunes JA, Olive D (2011) PD-L2 is expressed on 
activated human T cells and regulates their function. Mol Immunol 48 (15-16):2214-2219.

doi:10.1016/j.molimm.2011.06.436

17. Yearley JH, Gibson C, Yu N, Moon C, Murphy E, Juco J, Lunceford J, Cheng J, Chow LQM, Seiwert TY, Handa M, Tomassini JE, McClanahan T (2017) PD-L2 Expression in Human Tumors: Relevance to Anti-PD-1 Therapy in Cancer. Clin Cancer Res 23 (12):31583167. doi:10.1158/1078-0432.CCR-16-1761

18. Nazareth MR, Broderick L, Simpson-Abelson MR, Kelleher RJ, Yokota SJ, Bankert RB (2007) Characterization of Human Lung Tumor-Associated Fibroblasts and Their Ability to Modulate the Activation of Tumor-Associated T Cells. The Journal of Immunology 178 (9):5552-5562. doi:10.4049/jimmunol.178.9.5552

19. Taube JM, Klein A, Brahmer JR, Xu H, Pan X, Kim JH, Chen L, Pardoll DM, Topalian SL, Anders RA (2014) Association of PD-1, PD-1 ligands, and other features of the tumor immune microenvironment with response to anti-PD-1 therapy. Clin Cancer Res 20 (19):5064-5074. doi:10.1158/1078-0432.ccr-13-3271

20. Dong H, Zhu G, Tamada K, Flies DB, van Deursen JM, Chen L (2004) B7-H1 determines accumulation and deletion of intrahepatic CD8(+) T lymphocytes. Immunity 20 (3):327336

21. Clarke P, Mann J, Simpson JF, Rickard-Dickson K, Primus FJ (1998) Mice transgenic for 
human carcinoembryonic antigen as a model for immunotherapy. Cancer Res 58 (7):1469-

1477

22. Hirano F, Kaneko K, Tamura H, Dong H, Wang S, Ichikawa M, Rietz C, Flies DB, Lau JS, Zhu G, Tamada K, Chen L (2005) Blockade of B7-H1 and PD-1 by monoclonal antibodies potentiates cancer therapeutic immunity. Cancer Res 65 (3):1089-1096

23. Mazanet MM, Hughes CCW (2002) B7-H1 Is Expressed by Human Endothelial Cells and Suppresses T Cell Cytokine Synthesis. The Journal of Immunology 169 (7):3581-3588. doi:10.4049/jimmunol.169.7.3581

24. Pollard JW (2004) Tumour-educated macrophages promote tumour progression and metastasis. Nat Rev Cancer 4 (1):71-78. doi:10.1038/nrc1256

25. Horlad H, Ma C, Yano H, Pan C, Ohnishi K, Fujiwara Y, Endo S, Kikukawa Y, Okuno Y, Matsuoka M, Takeya M, Komohara Y (2016) An IL-27/Stat3 axis induces expression of programmed cell death 1 ligands (PD-L1/2) on infiltrating macrophages in lymphoma. Cancer Sci 107 (11):1696-1704. doi:10.1111/cas.13065

26. Liu J, Guan X, Ma X (2007) Regulation of IL-27 p28 gene expression in macrophages through MyD88- and interferon-gamma-mediated pathways. J Exp Med 204 (1):141-152. doi:10.1084/jem.20061440

27. Koyama S, Akbay EA, Li YY, Herter-Sprie GS, Buczkowski KA, Richards WG, Gandhi L, 
Redig AJ, Rodig SJ, Asahina H, Jones RE, Kulkarni MM, Kuraguchi M, Palakurthi S, Fecci PE, Johnson BE, Janne PA, Engelman JA, Gangadharan SP, Costa DB, Freeman GJ, Bueno R, Hodi FS, Dranoff G, Wong KK, Hammerman PS (2016) Adaptive resistance to therapeutic PD-1 blockade is associated with upregulation of alternative immune checkpoints. Nature communications 7:10501. doi:10.1038/ncomms10501

28. Sakuishi K, Apetoh L, Sullivan JM, Blazar BR, Kuchroo VK, Anderson AC (2010) Targeting Tim-3 and PD-1 pathways to reverse T cell exhaustion and restore anti-tumor immunity. J Exp Med 207 (10):2187-2194. doi:10.1084/jem.20100643

29. Woo SR, Turnis ME, Goldberg MV, Bankoti J, Selby M, Nirschl CJ, Bettini ML, Gravano DM, Vogel P, Liu CL, Tangsombatvisit S, Grosso JF, Netto G, Smeltzer MP, Chaux A, Utz PJ, Workman CJ, Pardoll DM, Korman AJ, Drake CG, Vignali DA (2012) Immune inhibitory molecules LAG-3 and PD-1 synergistically regulate T-cell function to promote tumoral immune escape. Cancer Res 72 (4):917-927. doi:10.1158/0008-5472.CAN-11-1620 30. Johnston RJ, Comps-Agrar L, Hackney J, Yu X, Huseni M, Yang Y, Park S, Javinal V, Chiu H, Irving B, Eaton DL, Grogan JL (2014) The immunoreceptor TIGIT regulates antitumor and antiviral CD8(+) T cell effector function. Cancer Cell 26 (6):923-937. doi:10.1016/j.ccell.2014.10.018 


\section{Figure Legends}

Fig. 1. Important role of PD-L1 on tumor and host cells in anti-tumor immune responses

Control or PD-L1-deficient MC38 tumor cells were inoculated s.c. into wild-type or PDL1-KO mice. a Tumor growth in each group is shown. Each line indicates the tumor size in individual mouse. Data are shown from two independent experiments. The number of tumor-rejected mice out of total mice is indicated. b Survival of the mice is shown. $\bigcirc$ : Wild-type mice inoculated with control MC38, $\triangle:$ Wild-type mice inoculated with PDL1-deficient MC38, @: PD-L1-KO mice inoculated with control MC38, $\mathbf{\Delta}$ : PD-L1-KO mice inoculated with PD-L1-deficient MC38. $\bigcirc$ vs. $\bigcirc ; \mathrm{P}=0.0005, \bigcirc$ vs. $\triangle$; $\mathrm{P}<$ $0.0001, \bigcirc$ vs. $\triangle ; \mathrm{P}=0.025, \triangle$ vs. $\boldsymbol{\Delta} ; \mathrm{P}=0.0006$

Fig. 2. Suppressive role of PD-L1 on BM-derived hematopoietic cells in anti-tumor immunity

$\mathrm{BM}$ chimeric mice generated by a transfer of PD-L1-KO BM cells into wild-type mice or vice versa were inoculated s.c. with PD-L1-deficient MC38. a Tumor growth in each group is shown. Each line indicates the tumor size in individual mouse. The number of 
tumor-rejected mice out of total mice is indicated. $\mathbf{b}$ Survival of the mice is shown. $\bigcirc$ :

PD-L1-KO BM transferred into wild-type mice, $\mathbf{\Delta}$ : Wild-type BM transferred into PD-

L1-KO mice. $\bigcirc$ vs. $\boldsymbol{\Delta} ; \mathrm{P}=0.0383$.

Fig. 3. Therapeutic effects of anti-PD-L1 and anti-PD-L2 mAbs in MC38

Wild-type mice were inoculated s.c. with MC38 and treated with anti-PD-L1 mAb alone, anti-PD-L2 mAb alone, or combination of these mAbs. Hamster IgG and rat IgG were used as control Abs. a Tumor growth in each group is shown. Each line indicates the tumor size in individual mouse. Data are shown from two independent experiments. The number of tumor-rejected mice out of total mice is indicated. $\mathbf{b}$ Survival of the mice is shown. $\bigcirc$ : Control Abs, $\triangle$ : Anti-PD-L1 mAb + control Ab, $\bigcirc$ : Anti-PD-L2 mAb + control Ab, $\boldsymbol{\Delta}$ : Anti-PD-L1 mAb + anti-PD-L2 mAb. $\bigcirc$ vs. $\bigcirc ; \mathrm{P}=0.121, \bigcirc$ vs. $\triangle ; \mathrm{P}<$ $0.0001, \triangle$ vs. $\mathbf{\Delta} ; \mathrm{P}=0.011$

Fig. 4. Inducible expression of PD-L2 on TAM by anti-PD-L1 mAb treatment

Wild-type mice were inoculated s.c. with MC38 and treated with anti-PD-L1 mAb or 
control Ab. Tumor tissues were harvested and analyzed for the expression of PD-L2 on TAM, non-TAM immune cells, and CD45-negative non-immune cells by flow cytometry. a Representative histograms are shown. The filled and solid lines indicate unstained controls and stained samples, respectively. b Percentages of PD-L2 positive cells in TAM, non-TAM immune cells, and CD45-negative non-immune cells were analyzed. Data are shown as mean \pm SEM of 10 or 8 mice per group. Data are shown from two independent experiments. ${ }^{* *} \mathrm{P}=0.0054$, NS: not significant.

Fig. 5. Induction of tumor-specific memory response by treatment with anti-PD-L1 and anti-PD-L2 mAbs

The mice inoculated with MC38 were treated with both anti-PD-L1 and anti-PD-L2 mAbs to induce tumor regression. After 3 months, the tumor-rejected mice $(\bigcirc)$ were rechallenged s.c. with MC38 and B16F10 on the right and left lateral flank, respectively. As a control, naïve C57BL/6 mice () were also inoculated s.c. with MC38 and B16F10 in the same manner. Tumor sizes were measured and is shown as the mean $\pm \mathrm{SD}$ of 5 or 6 mice per group. 
Fig. 6. Combined treatment with anti-PD-L1 and anti-PD-L2 mAbs in 3LL lung tumor model

The mice were inoculated s.c. with $3 \mathrm{LL}$ and treated with anti-PD-L1 mAb alone, antiPD-L2 mAb alone, or combination of these mAbs. Hamster IgG and rat IgG were used as control Abs. a Tumor growth in each group is shown as the mean \pm SD of 5 mice per group. *: $\mathrm{P}<0.05$. b Survival of the mice is shown. $\bigcirc$ : Control Abs, $\triangle$ : Anti-PD-L1 mAb + control Ab, : Anti-PD-L2 mAb + control Ab, $\mathbf{\Delta}$ : Anti-PD-L1 mAb + anti-PD-L2 mAb. $\bigcirc$ vs. $\boldsymbol{\Delta} ; \mathrm{P}=0.013, \triangle$ vs. $\boldsymbol{\Delta} ; \mathrm{P}=0.021, \bigcirc$ vs. $\boldsymbol{\Delta} ; \mathrm{P}=0.021$ 
a
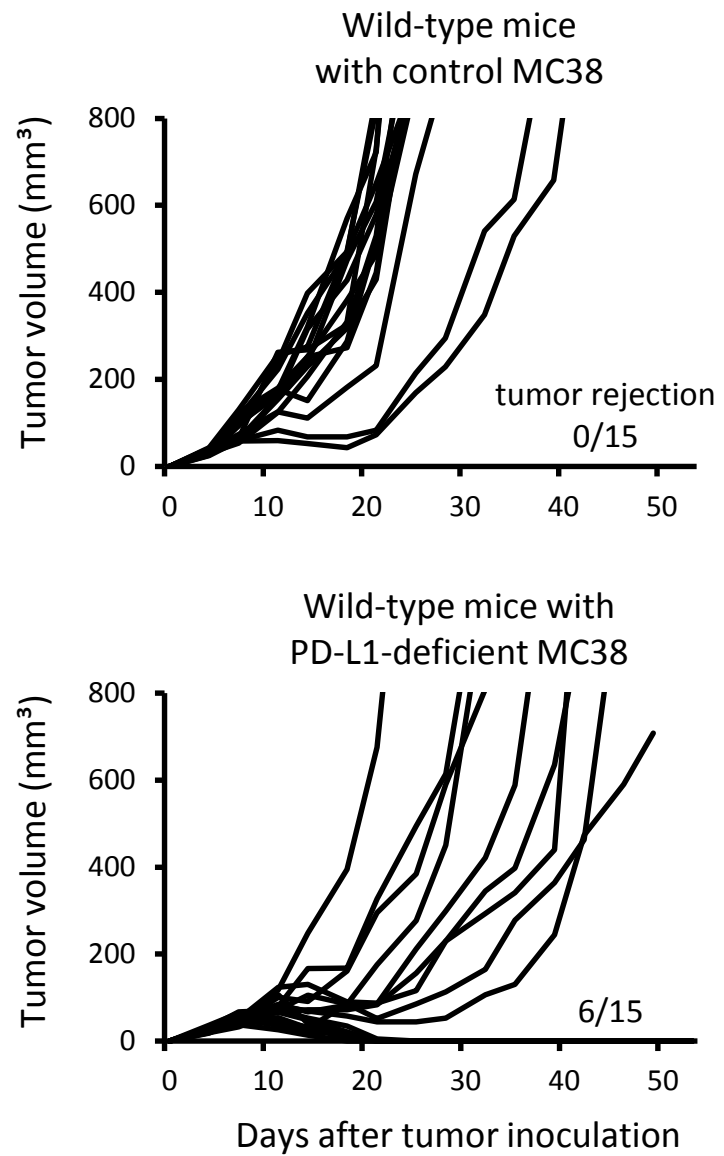

PD-L1-KO mice with control MC38

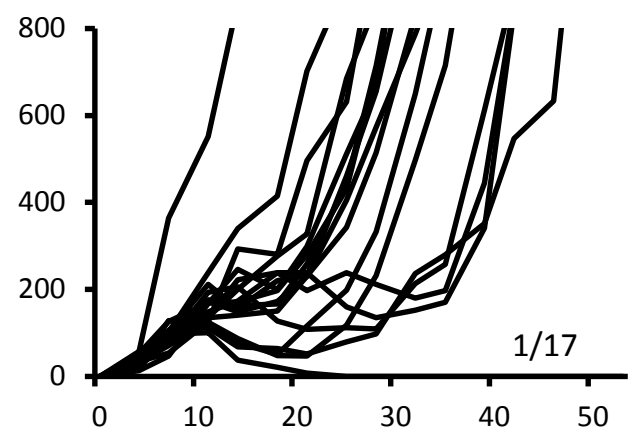

PD-L1-KO mice with PD-L1-deficient MC38

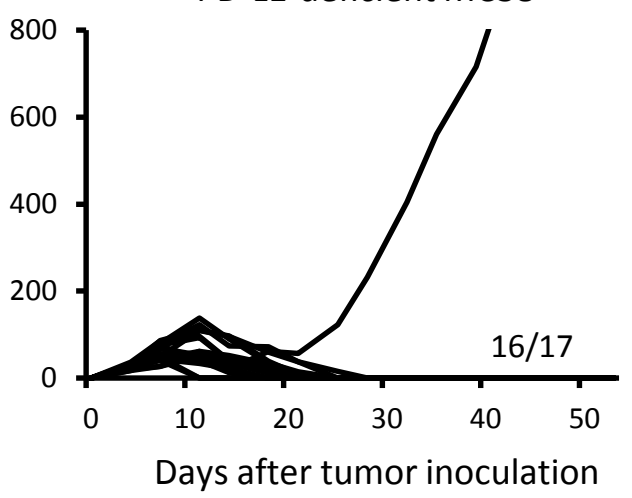

b

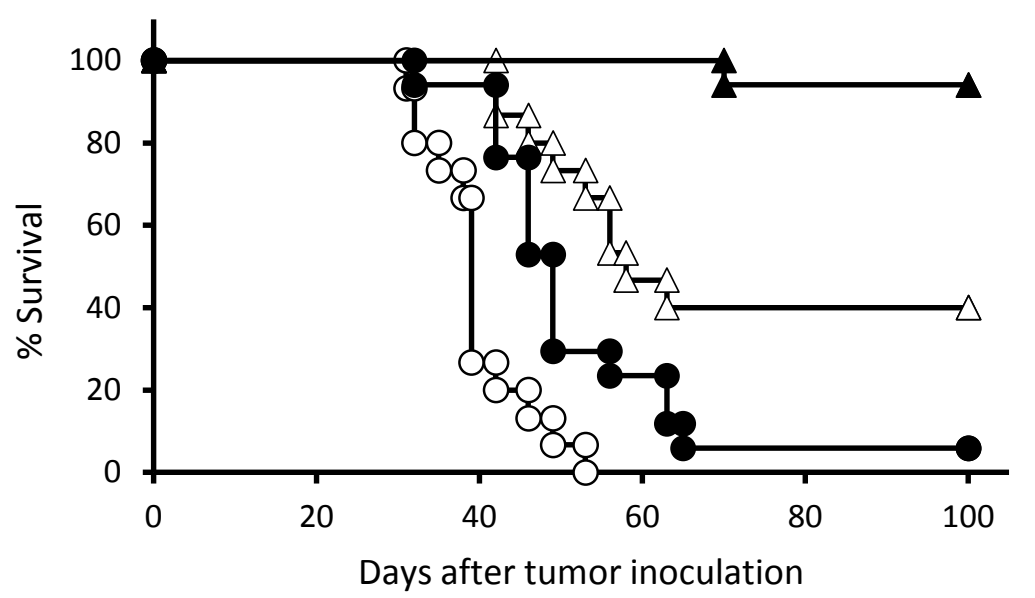

Figure 1

D. Umezu et al. 
a
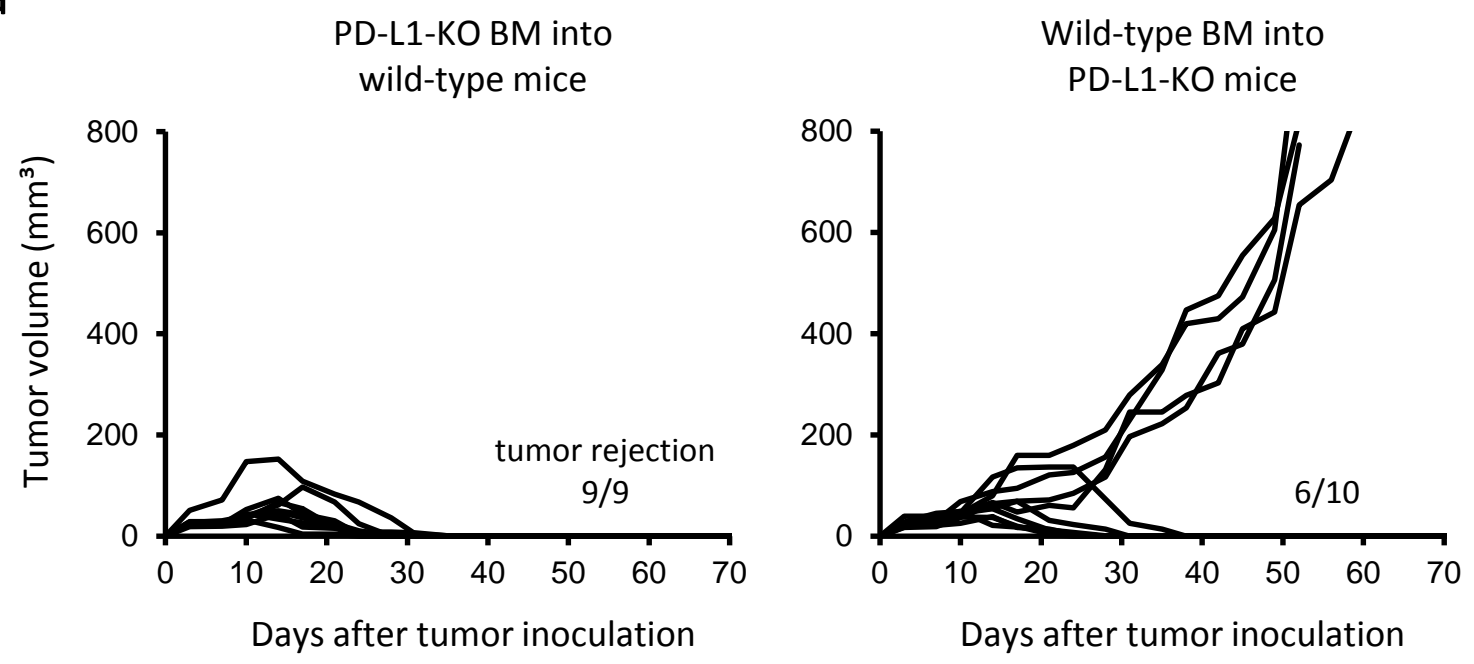

b

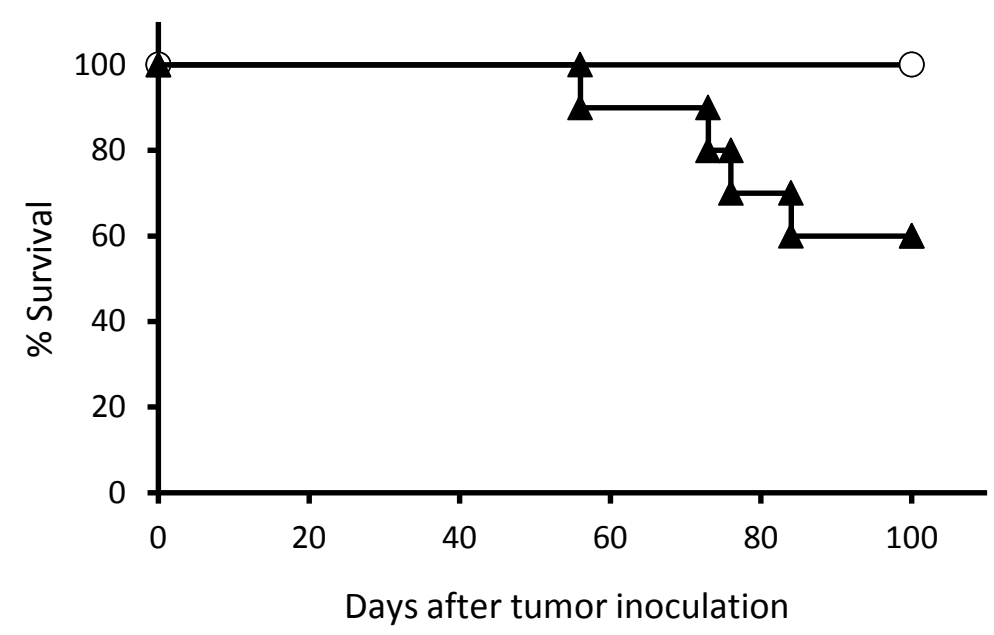

Figure 2 
a
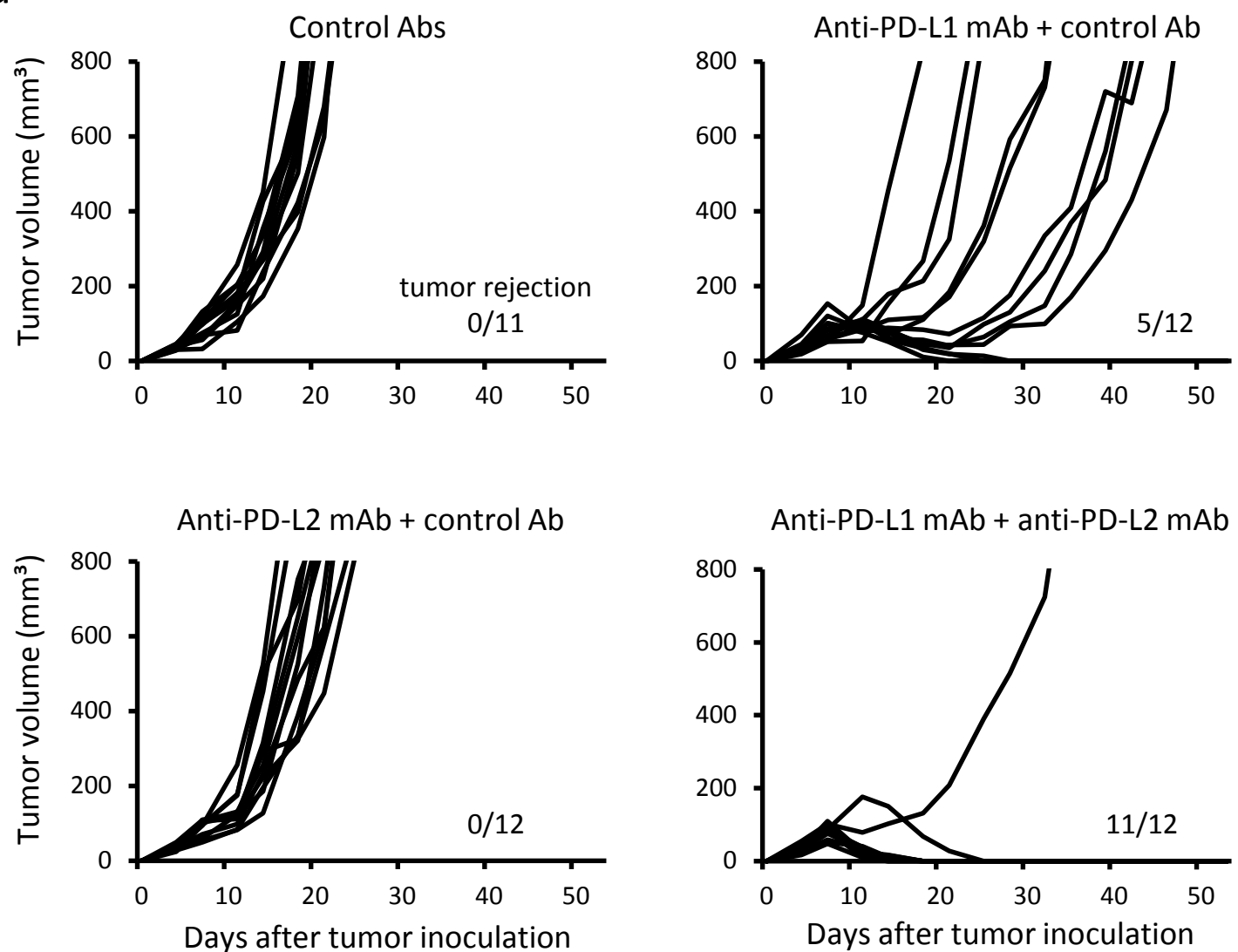

b

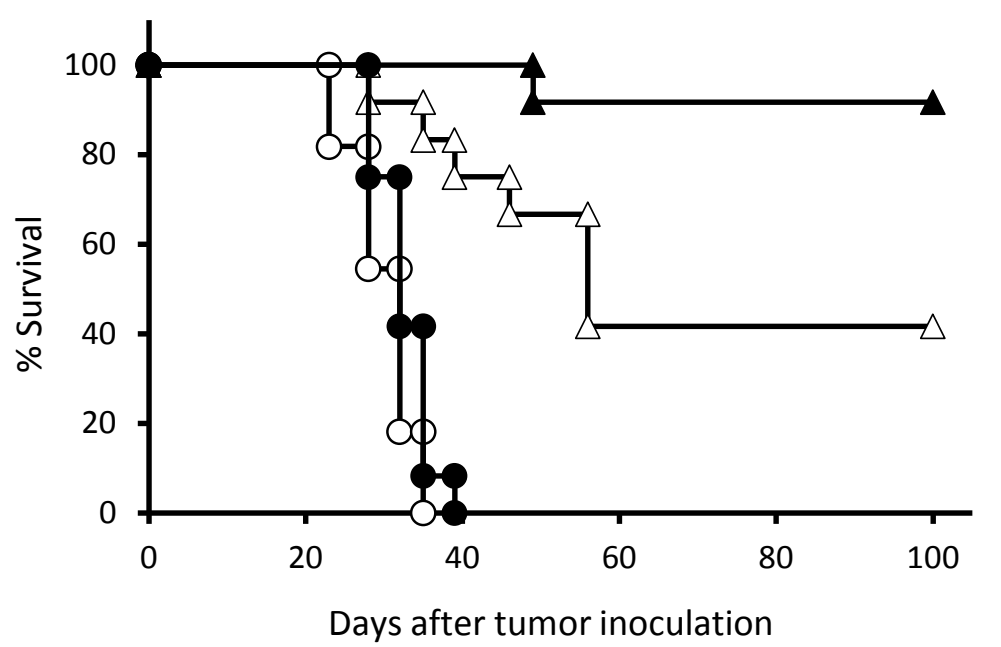

Figure 3

D. Umezu et al. 
a

Anti-PD-L1 $\mathrm{mAb}$

(TAM)
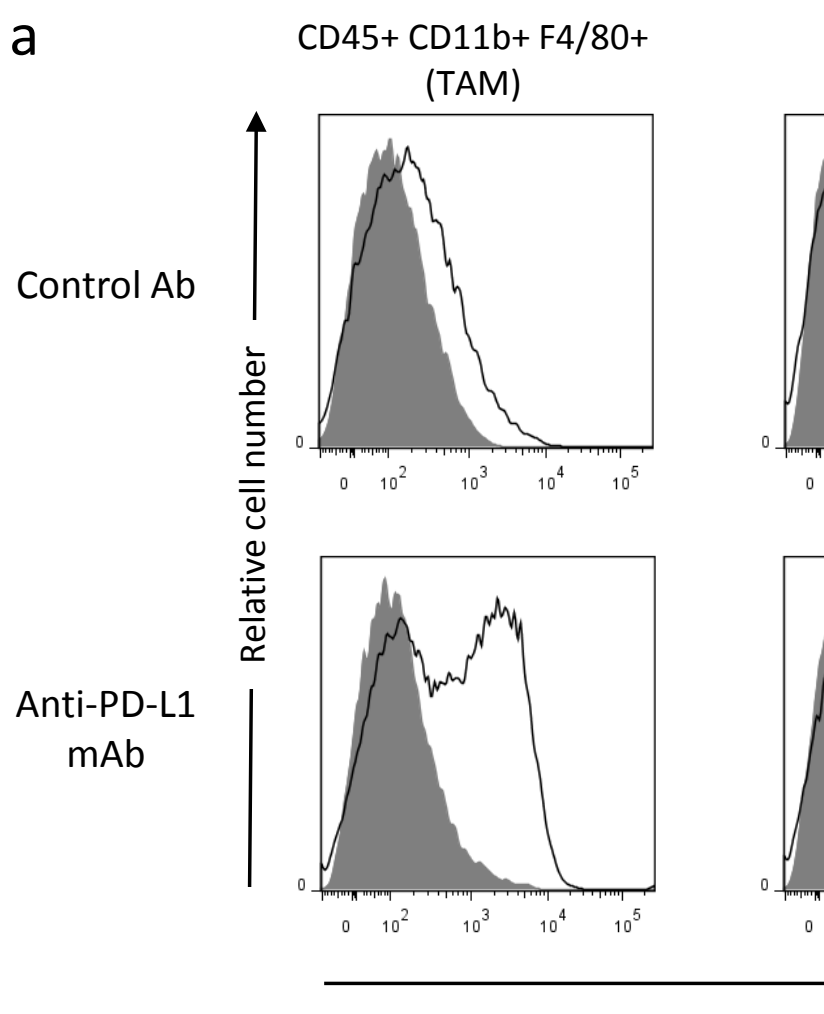

Non-TAM
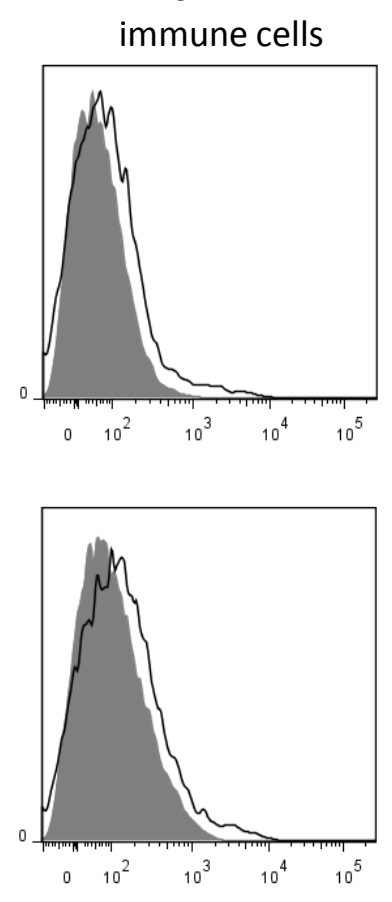

PD-L2

b

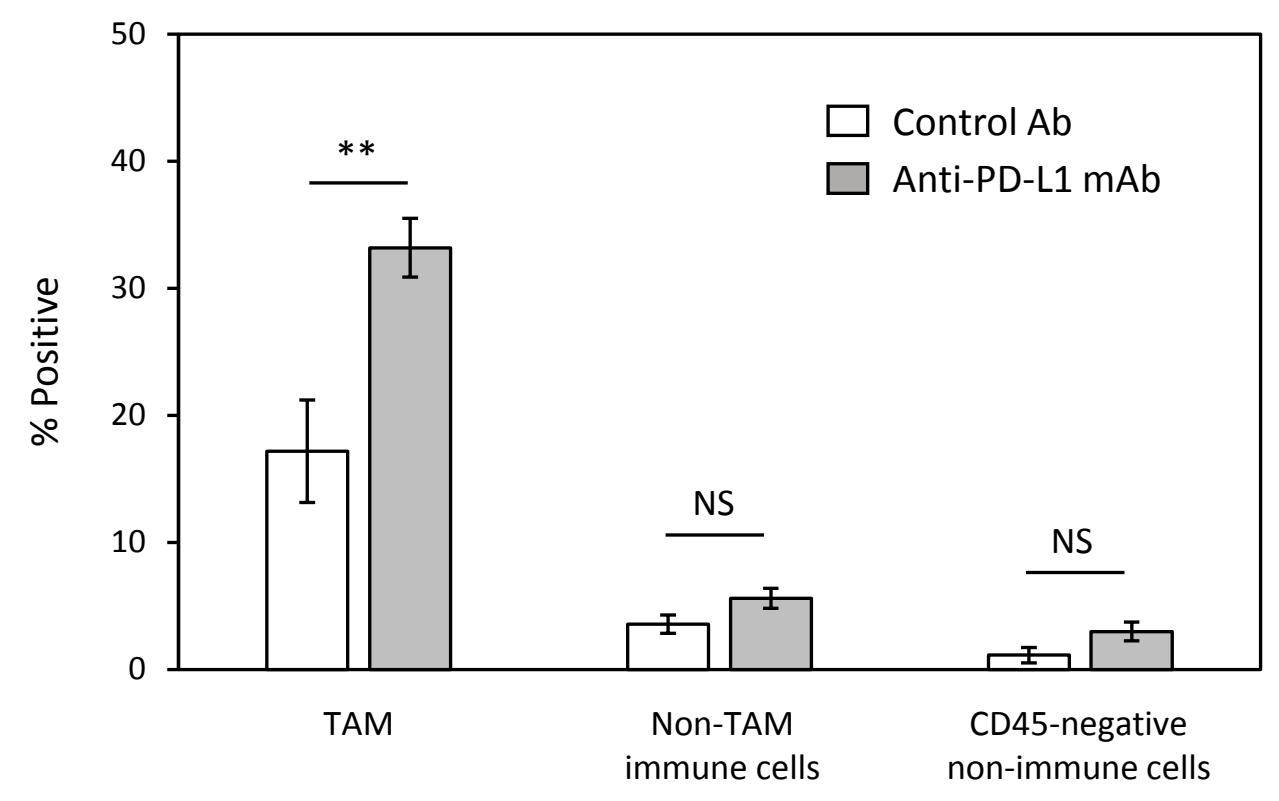

Figure 4

D. Umezu et al. 

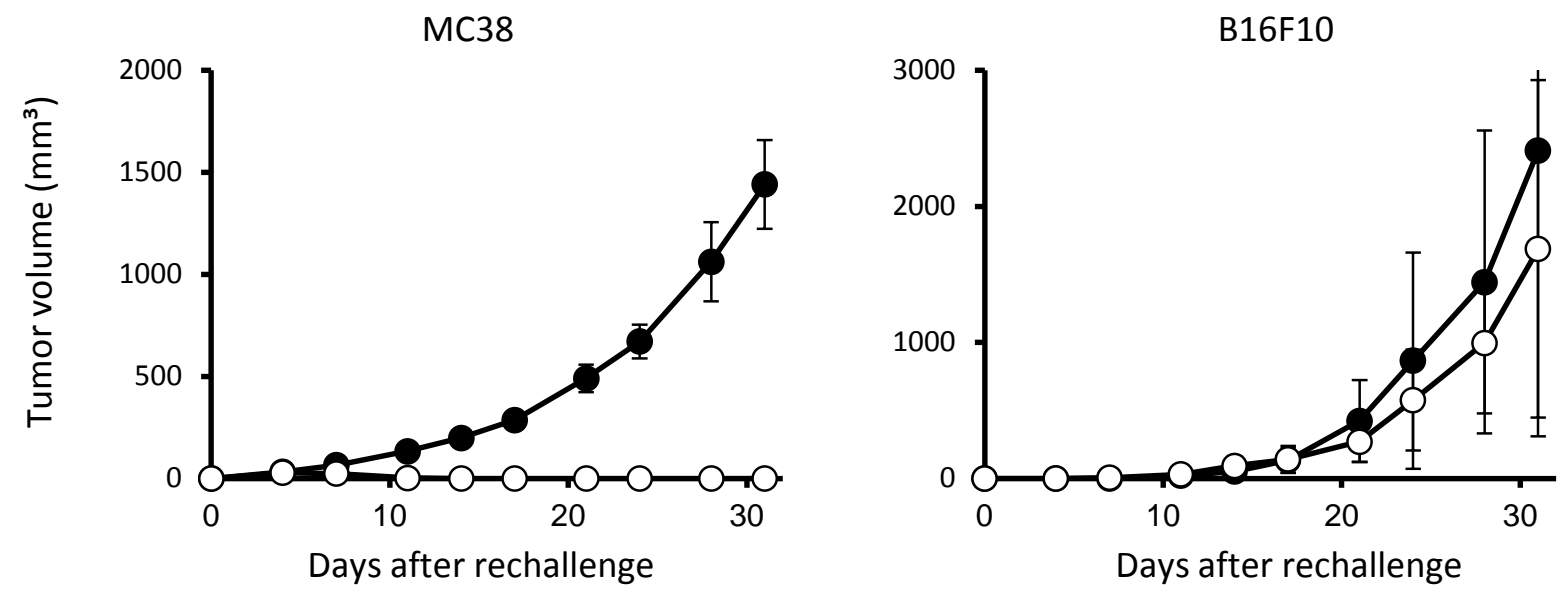

Figure 5

D. Umezu et al. 

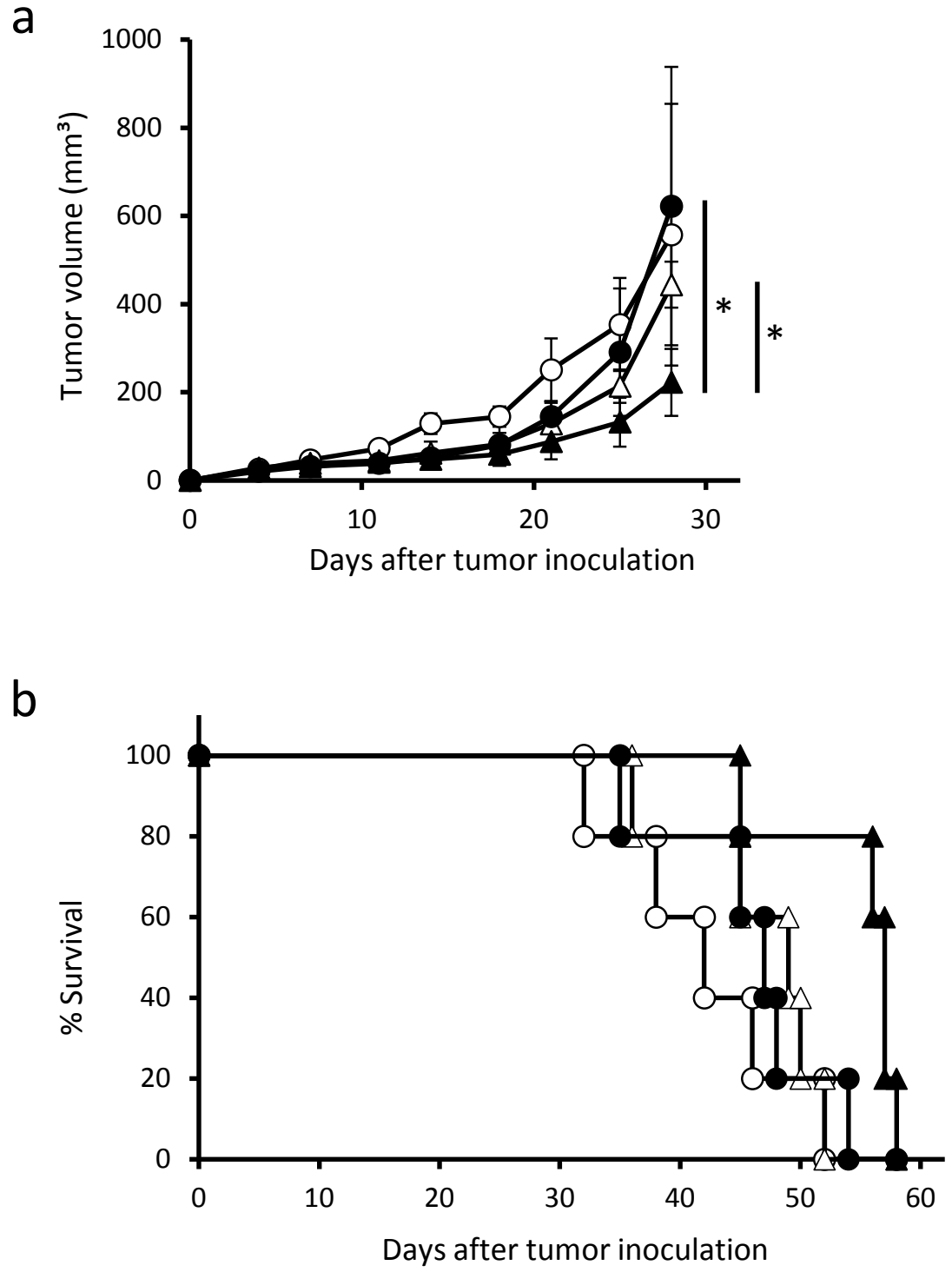

Figure 6

D. Umezu et al. 
a

IFN- $\gamma(-)$

$\operatorname{IFN}-\gamma(+)$

Control MC38
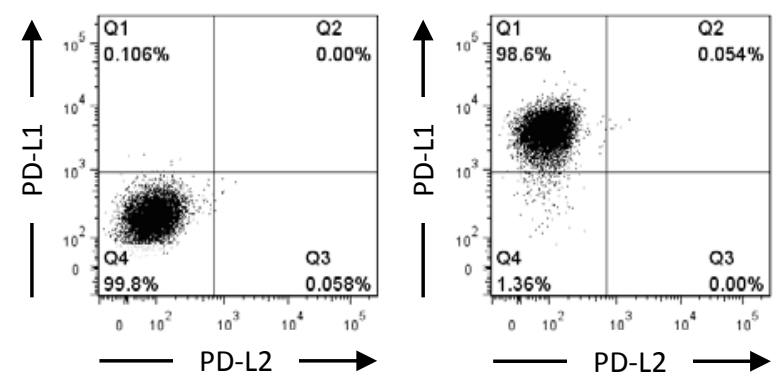

PD-L1-deficient MC38
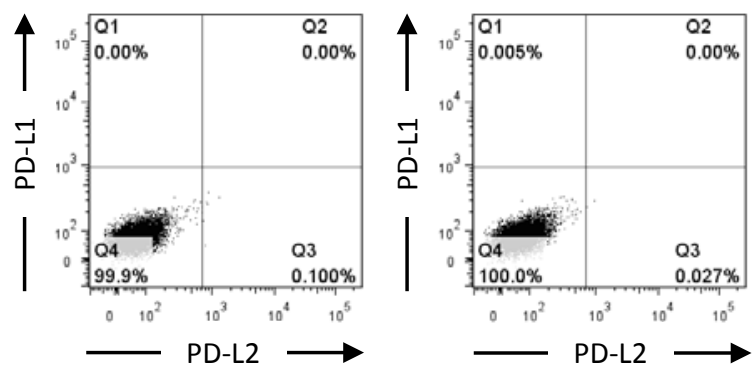

b

Control MC38

PD-L1-deficient MC38
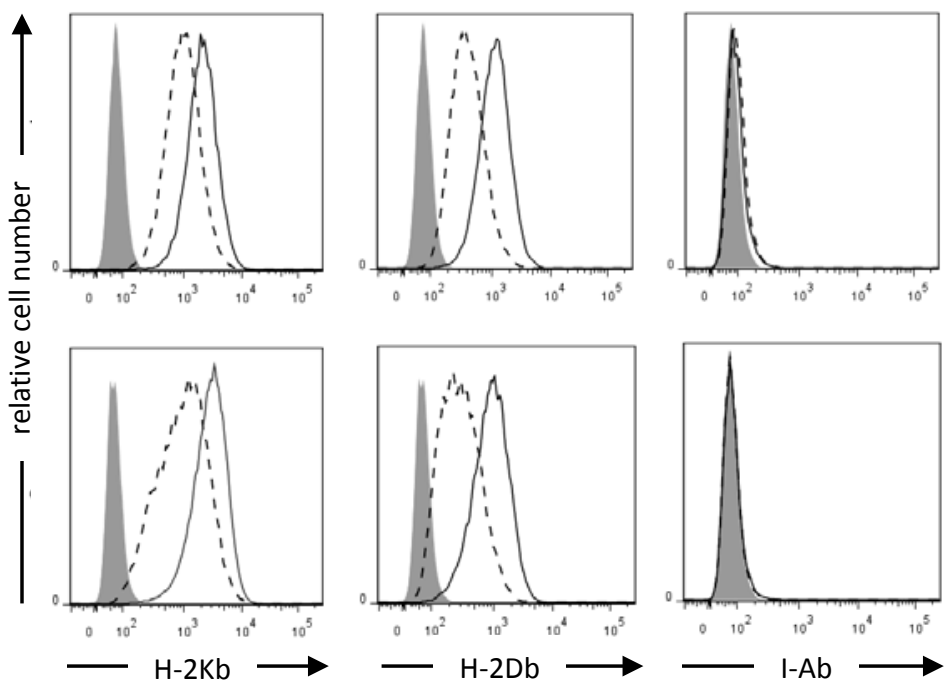

\section{Supplementary Fig. 1. Phenotypic analyses of PD-L1-deficient MC38 tumor cells}

a PD-L1 and PD-L2 expressions of control MC38 (top) or PD-L1-deficient MC38 (bottom) were analyzed by flow cytometry. Tumor cells were untreated (left) or treated with $1000 \mathrm{U} / \mathrm{ml}$ IFN- $\nu$ for 24 hours (right) prior to the analysis. b Expressions of MHC class I $\left(\mathrm{H}-2 \mathrm{~K}^{\mathrm{b}}\right.$ and $\left.\mathrm{H}-2 \mathrm{D}^{\mathrm{b}}\right)$ and

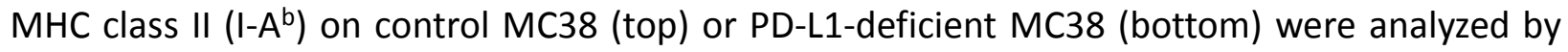
flow cytometry. Tumor cells were untreated (dashed line) or treated with $1000 \mathrm{U} / \mathrm{ml} \mathrm{IFN-} \gamma$ for 24 hours (solid line) prior to the analysis. The filled histogram indicates the unstained control. 